\title{
Proposed Libyan Guidelines for the Management of Inpatient Hyperglycemia with Corona Virus-19 (COVID-19) Infection
}

\author{
Adela H. Elamami ${ }^{1,2}$ \\ ${ }^{1}$ Internal Medicine Department, Benghazi University, Benghazi, Libya \\ ${ }^{2}$ Diabetes and Endocrine Unit, Hawari Teaching Hospital, Benghazi, Libya \\ Email: elamamiadela@yahoo.com, adela.ebsat@uob.edu.ly
}

How to cite this paper: Elamami, A.H. (2021) Proposed Libyan Guidelines for the Management of Inpatient Hyperglycemia with Corona Virus-19 (COVID-19) Infection. Open Journal of Epidemiology, 11, 237-244.

https://doi.org/10.4236/ojepi.2021.113020

Received: April 20, 2021

Accepted: July 20, 2021

Published: July 23, 2021

Copyright $\odot 2021$ by author(s) and Scientific Research Publishing Inc. This work is licensed under the Creative Commons Attribution International License (CC BY 4.0). http://creativecommons.org/licenses/by/4.0/

\section{Open Access}

\begin{abstract}
Serious hyperglycemia is one of the manifestations of COVID-19 infection which increase patient morbidity and mortality especially in patient requiring hospitalization. Consequently, many protocols and algorithms for hospitalized patients with COVID-19 induced hyperglycemia based mainly on recent studies and previous evidence on non-COVID-19 patients were published. Of note nearly all guidelines released by the different COVID-19 committees in Libya don't include a clear focus on management of in-patient hyperglycemia and maybe this plays a pivotal role in increase our COVID-19 in-hospital mortality. I proposed a simplified approach depending on the released international guidelines to be easily implemented by Libyan health care staff caring about COVID-19 patients and hoping to be accepted by our National Diabetes Committee.
\end{abstract}

\section{Keywords}

In-Patient Hyperglycemia, COVID-19, Management, Proposed Guideline, Libya

\section{Introduction}

As all the studies show that glycemic control is one of the major predictors of the mortality in corona virus-19 infections (COVID-19) [1] [2] [3], that's why implementing an effective glycemic control guideline is extremely important [4]. It's well known that well-controlled blood glucose (BG) levels, defined as BG between 70 and $180 \mathrm{mg} / \mathrm{dL}$ ( 3.9 and $10.0 \mathrm{mmol} / \mathrm{L}$ ) have been associated with reduced major organ failure and all-cause mortality [5]. Many recent published 
guidelines and approaches for the management of blood sugar for in and out COVID-19 patients were implemented [6] [7] [8] [9] [10]. We try to choose the most reasonably applicable method of glycemic control that can easily be implemented by health care staff especially those dealing with COVID-19 in-patients in Libya. The number of confirmed cases of COVID-19 infection in Libya by June 2021 was 176.701 and the total death was 3116 [11].

\section{Management of Hyperglycemia in Critically Ill Patient with COVID-19 Infection in ICU}

\subsection{Management of DKA in COVID-19 Infection Patients}

Most of the guidelines modified the DKA management protocol to effectively treat serious hyperglycemia and in mean time reducing the risk of exposure of health staff and this especially critical as there is shortage of protective equipment and nursing staff in Libya. The corner of this modification was the use of the Subcutaneous approach rather than intravenous one in patient who are not severely acidotic $\left(\mathrm{pH}>7, \mathrm{HCO}_{3}>10\right)$ and non-pregnant female. Also, the use of insulin analogue, the long acting once daily and rapid acting every 3 hours by most of the published guidelines especially in conscious patient with mild to moderate DKA who can inject himself and even can check his finger stick blood sugar (FS) by use of reliable glucometer was of paramount in managing DKA while reducing the burden on heath staff. This approach actually not new as many studies proved that this approach was effective and safe previously in non-COVID 19 Mild to moderate uncomplicated DKA patients [12] [13] [14] [15] [16]. Studies show that use of lower fluid rate in COVID-19 patient admitted with DKA is important compared to the rate used for non-COVID-19 patients even in patient on steroids they usually increase the insulin doses by $50 \%$ rather than fluid rate. Patients with ESRD (End stage renal disease) need lower doses of insulin by nearly half [9] [10].

Many modified DKA approach was published recently. We try to put an algorithm derived from all these published protocols which is easy to apply in Libyan health care systems.

\subsubsection{Mild to Moderate DKA}

The patient can be managed with subcutaneous insulin approach with use of insulin analogues [9] [10].

The patient should meet all the following criteria to start SQ insulin protocol: [10]

1) Blood gas (venous or arterial) $\mathrm{pH} \geq 7.0$.

2) Serum bicarbonate $\geq 10 \mathrm{mEq} / \mathrm{L}$.

3) Alert/Awake mental status.

4) MAP > 65 after 1 L IV fluids.

5) $\mathrm{K} \geq 3.3 \mathrm{mEq} / \mathrm{L}$.

6) The patient is not. Pregnant, Acute CHF (Congestive heart failure) Exacerbation, Acute Coronary Syndrome, ESRD or CKD Stage 4 or 5, Acute Liver 
Failure or Cirrhosis, Anasarca, Weight $>120 \mathrm{~kg}$, High-dose Corticosteroids. In all these patients, you can use the same fluid rate and electrolyte correction but with Iv insulin protocol with either increase $50 \%$ insulin dose in obese and patient on high steroid or decrease to half dose in patient with ESRD and Liver cirrhosis.

Note: Patients who are stable ESRD and patient on lower steroid dose may be safely managed with SQ insulin approach.

The approach is illustrated in Figure 1.

\subsubsection{Patient with Severe DKA}

The main difference in the management is the use of IV insulin protocol and higher fluid rate starting with $1 \mathrm{~L} /$ first hour and then to rate $200-400 \mathrm{ml} /$ hour according to fluid status. The approach is illustrated below [9] [10] (Figure 2).

\subsubsection{Management of Electrolyte}

Replace Potassium $\mathrm{K}^{+}$if less than $<5.1 \mathrm{mEq} / \mathrm{L}$, Magnesium $\mathrm{Mg}^{+}$if less than $<1.5$, Phosphorous $\mathrm{Ph}$ if less than $<1$, Always correct Sodium $\mathrm{Na}^{+}$for hyperglycemia and change the fluid type accordingly to either 0.45 NS or free water. Table 1 illustrates potassium replacement rate [10].

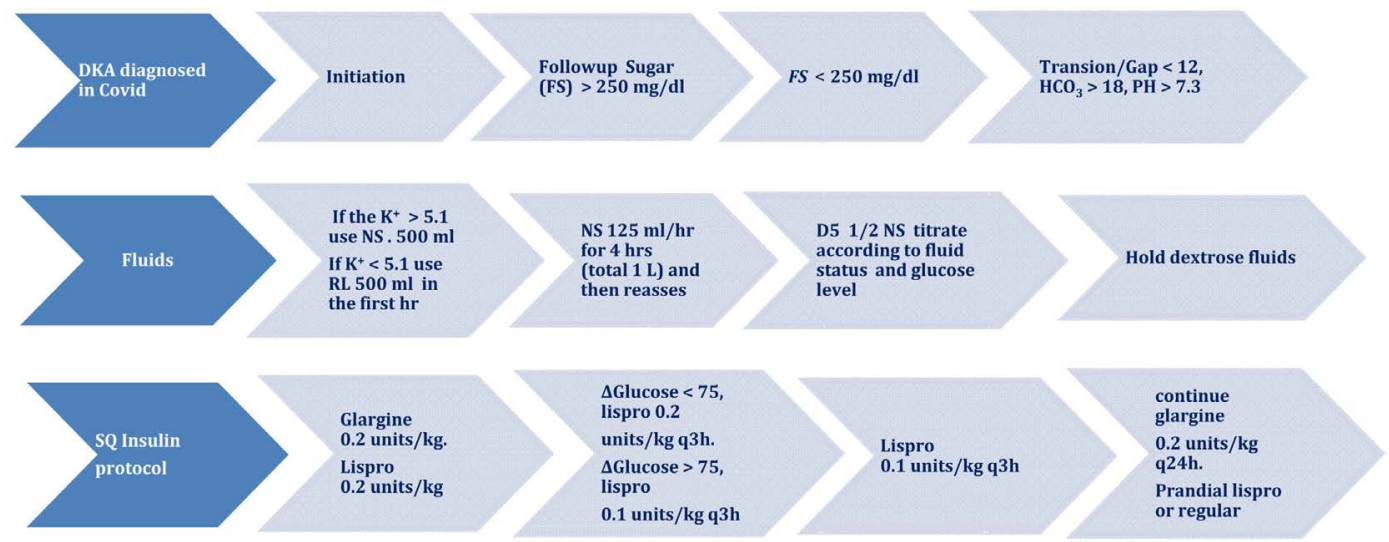

Figure 1. Management of mild to moderate DKA in COVID-19 patients. Adopted from MSHS COVID-19 DKA Protocol [9].

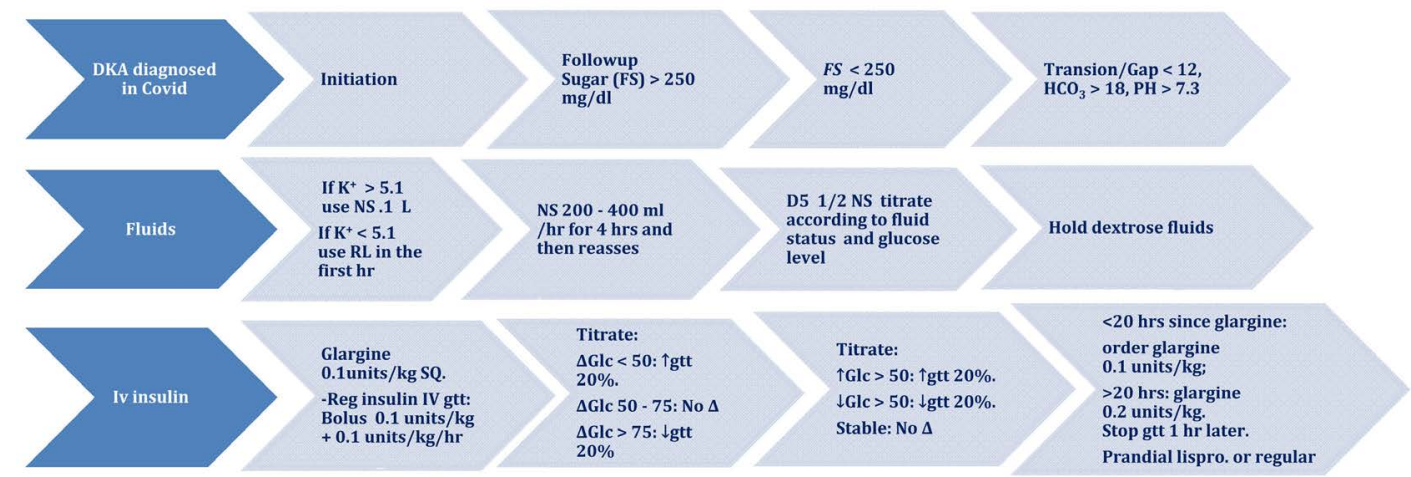

Figure 2. Management of severe DKA in COVID-19 patients. Adopted from MSHS COVID-19 DKA and Montefiore DKA Protocol. (gtt.: Abbreviation meaning drops) 
Table 1. Management of potassium in COVID-19 patients. Adopted from Montefiore DKA protocol.

\begin{tabular}{cc}
\hline $\mathrm{K}<3.3$ & $\begin{array}{c}\text { Hold insulin until }>3.3 \text { administer } 60 \mathrm{mEq} / \mathrm{L} \text { rider, } \\
\text { consider central line for rapid } 20 \mathrm{mEq} / \mathrm{hr} \mathrm{KCL} \text { infusion. }\end{array}$ \\
$>3.3-4$ & Add $40 \mathrm{mEq} \mathrm{KCl} / \mathrm{L} \mathrm{IVF}$. \\
$4.1-5$ & Add $20 \mathrm{mEq} \mathrm{KCl} / \mathrm{L}$ IVF. \\
$>5.1$ & Don't give $\mathrm{K}$ and re check q $2-4 \mathrm{hrs}$ \\
\hline
\end{tabular}

\subsection{Management of Hyperglycemia in Critically Ill Patient without DKA}

Generally, the target is to keep the blood sugar in range of $140-180 \mathrm{mg} / \mathrm{dl}$ with minimal or no hypoglycemia [5] [17]. The preferred way is by using SQ approach with basal and correction doses unless the patient is hemodynamically unstable, on TPN (total parenteral nutrition making his insulin doses unstable) where insulin infusion protocol is needed with blood glucose every one hour is mandatory [7].

When the patient becomes hemodynamically stable change the patient to basal-correction doses as soon as possible to limit the nurse contact. The initial dose of subcutaneous insulin administration at the time of transition can be determined as $60 \%-80 \%$ of the insulin administered intravenously during the preceding $24 \mathrm{~h}$. To avoid rebound hyperglycemia after transition, a sufficient duration of overlap with the insulin infusion and the subcutaneous insulin administration is required. Short-acting insulin can be administered 1 to $2 \mathrm{~h}$ and long-acting insulin 2 to $3 \mathrm{~h}$ prior to discontinuation of intravenous insulin administration [7].

Patients who are hemodynamically stable and not on high dose steroid at admission better to be managed with basal-correction doses or even basal-bolus, with correction doses with blood glucose monitored every $4-6$ hours preferably by finger stick [7].

\section{Management of Hyperglycemia in Non-Critically Ill Patient in General Ward}

The glycemic target is $110-180 \mathrm{mg} / \mathrm{dl}$ in most of patients but a level of $110-140$ $\mathrm{mg} / \mathrm{dl}$ is reasonable if can be reached without significant hypoglycemia [7].

\subsection{Patient Who Is Not Taking Orally [18]}

T1D (Type 1 diabetes).

T2D (Type 2 diabetes) on oral or insulin therapy.

Unknown with Admitted BG > $180 \mathrm{mg} / \mathrm{dl}$.

In all these patients use basal-correction insulin doses and follow BG every 4 6 hrs.

\subsection{Patient Who Is Taking Orally}

Use basal-bolus plus correction doses and they should check BG before meals 
and at bed time.

Type 2 diabetics who was well controlled on diet control and there admitted BG $<180$ can be managed in the first 24 hrs. With correction doses only to calculate their insulin requirements and then you can step up to adding basal insulin or basal bolus according to his oral intake.

\section{How to calculate basal bolus regimen:}

1) Patients who were on this regimen as outpatients and was with good glycemic control continue in hospital with same dose and adjust according to Finger stick sugar (FS).

2) Patients who are insulin naïve Total daily dose (TDD) calculated at $0.4 / \mathrm{kg} /$ day [7].

3) Patients with higher risk of hypoglycemia like patient with renal dysfunction, autonomic neuropathy, liver disease, cardiac disease. Elderly above $>65$ years, hypoglycemia unawareness their TDD should be calculated at $0.2 / \mathrm{kg} / \mathrm{day}$ [7].

4) If human insulin is used the TDD should be divided into 4 portions (25\% each), three before each meal of regular insulin and one basal NPH [19].

5) If analogues are used the TDD should be divided $50 \%$ basal analogues (Glargine $100 \mathrm{IU}$, Glargine $300 \mathrm{IU}$, detemir or Tresiba) and 50\% of prandial insulin [19].

6) Prandial insulin analogues (Aspart, Lispro, Glulisine) which further divided into three doses equal before each meal.

\section{How to calculate correction doses:}

In patient who is NPO or not eating correction doses should be used in addition of basal insulin. Basal insulin is calculated as above. Correction doses calculated depending on blood glucose each 4 - 6 hrs using the following formula:

The patient blood glucose-120/Correction factor.

Correction factor is depending on the TDD. Correction factor indicates the decrease in blood glucose $(\mathrm{mg} / \mathrm{dl})$ expected with 1 unit of short acting insulin.

The correction dose is also required in patient who is eating to adjust for the Pre-meal blood glucose if more than $200 \mathrm{mg}$.

The following table shows the correction factor for each TDD insulin requirement per KG body weight [7] (Table 2).

Table 2. The correction factor for each TDD insulin requirement per KG body weight. Adopted from Bhawna et al., Diabetes Ther (2020).

\begin{tabular}{cc}
\hline TTD (total daily dose) units/kg/day) & Correction factor $(\mathrm{mg} / \mathrm{dl})$ \\
\hline$<0.5$ & 50 \\
0.5 to $<1$ & 40 \\
1 to $<1.5$ & 30 \\
$1.5-2$ & 20 \\
$>2$ & Consider intravenous insulin infusion
\end{tabular}

Note: Patient who is in transition from Insulin infusion should be managed with either Basal, correction doses if he is not eating or basal, bolus with correction if he starts to eat [20]. 


\section{Oral Anti-Diabetic Therapy in Hospitalized Patient with COVID-19}

As regard to use of oral therapy in hospitalized COVID-19 patients, the data are either not enough to justify safety or showing harmful effects. However, DDP4 inhibitor has reasonable evidence that supports its use in patient with mild to moderate COVID-19 infection in addition to basal insulin in absence of significant organ function defect [21]. Most of this evidence comes from studies conducted in non-COVID patients [22] [23]. Of note two recent studies show no positive prognostic outcome from the use of DPP4I in type 2 diabetics before admission with COVID-19 infection [24] [25]. Sulphonyl urea, Thiazolidinedione's (TZD), Metformin, SGLT2 inhibitors all should be discontinued in hospital [26].

\section{Conflicts of Interest}

No.

\section{References}

[1] Zhang, Y., Cui, Y., Shen, M., et al. (2020) Association of Diabetes Mellitus with Disease Severity and Prognosis in COVID-19: A Retrospective Cohort Study. Diabetes Research and Clinical Practice, 165, Article ID: 108227. https://doi.org/10.1016/j.diabres.2020.108227

[2] Roncon, L., Zuin, M., Rigatelli, G. and Zuliani, G. (2020) Diabetic Patients with COVID-19 Infection Are at Higher Risk of ICU Admission and Poor Short-Term Outcome. Journal of Clinical Virology, 127, Article ID: 104354. https://doi.org/10.1016/j.jcv.2020.104354

[3] Zhu, L., She, Z.-G., Cheng, X., et al. (2020) Association of Blood Glucose Control and Outcomes in Patients with COVID-19 and Pre-Existing Type 2 Diabetes. Cell Metabolism, 31, 1068-1077.e3. https://doi.org/10.1016/j.cmet.2020.04.021

[4] Wang, A., Zhao, W., Xu, Z. and Gu, J. (2020) Timely Blood Glucose Management for the Outbreak of 2019 Novel Coronavirus Disease (COVID-19) Is Urgently Needed. Diabetes Research and Clinical Practice, 162, Article ID: 108118. https://doi.org/10.1016/j.diabres.2020.108118

[5] NICE-SUGAR Study Investigators, Finfer, S., Chittock, D.R., et al. (2009) Intensive versus Conventional Glucose Control in Critically Ill Patients. The New England Journal of Medicine, 360, 1283-1297. https://doi.org/10.1056/NEJMoa0810625

[6] Zhou, K., Al-Jaghbeer, M.J. and Lansang, M.C. (2020) Hyperglycemia Management in Hospitalized Patients with COVID-19. Cleveland Clinic Journal of Medicine. [Online Ahead of Print] https://doi.org/10.3949/ccjm.87a.ccc012

[7] Attri, B., Goyal, A., Gupta, Y. and Tandon, N. (2020) Basal-Bolus Insulin Regimen for Hospitalized Patients with COVID-19 and Diabetes Mellitus: A Practical Approach. Diabetes Therapy, 11, 2177-2194. https://doi.org/10.1007/s13300-020-00873-3

[8] Rayman, G., Lumb, A., Kennon, B., et al. (2020) New Guidance on Managing Inpatient Hyperglycaemia during the COVID-19 Pandemic. Diabetic Medicine, 37, 1210-1213. https://doi.org/10.1111/dme.14327

[9] Lam, D.W., Leibner, E., Leiter, A., Levy, C.J., O’Malley, G., Radparvar, S. and Shah, 
N. (2020) MSHS COVID-19 DKA Protocol.

https://professional.diabetes.org/sites/professional.diabetes.org/files/media/ada-mo ntefiore_dka_protcol_version_3.0_5_22_20.pdf

[10] Agarwal, S., Crandall, J. and Tomer, Y. (2020) Montefiore Subcutaneous Insulin DKA Protocol.

https://professional.diabetes.org/sites/professional.diabetes.org/files/media/ada-mo ntefiore_dka_protcol_version_3.0_5_22_20.pdf

[11] Libya WHO Corona Virus Disease (COVID-19) Dashboard. https://covid19.who.int/region/emro/country/ly

[12] Umpierrez, G.E., Cuervo, R., Karabell, A., Latif, K., Freire, A.X. and Kitabchi, A.E. (2004) Treatment of Diabetic Ketoacidosis with Subcutaneous Insulin Aspart. Diabetes Care, 27, 1873-1878. https://doi.org/10.2337/diacare.27.8.1873

[13] Umpierrez, G.E., Latif, K., Stoever, J., et al. (2004) Efficacy of Subcutaneous Insulin Lispro versus Continuous Intravenous Regular Insulin for the Treatment of Patients with Diabetic Ketoacidosis. The American Journal of Medicine, 117, 291-296. https://doi.org/10.1016/j.amjmed.2004.05.010

[14] Ersöz, H.O., Ukinc, K., Köse, M., et al. (2006) Subcutaneous Lispro and Intra-Venous Regular Insulin Treatments Are Equally Effective and Safe for the Treatment of Mild and Moderate Diabetic Ketoacidosis in Adult Patients. International Journal of Clinical Practice, 60, 429-433. https://doi.org/10.1111/j.1368-5031.2006.00786.x

[15] Karoli, R., Fatima, J., Salman, T., Sandhu, S. and Shankar, R. (2011) Managing Diabetic Ketoacidosis in Non-Intensive Care Unit Setting: Role of Insulin Analogs. Indian Journal of Pharmacology, 43, 398-401. https://doi.org/10.4103/0253-7613.83109

[16] Razavi, Z., Maher, S. and Fredmal, J. (2018) Comparison of Subcutaneous Insulin Aspart and Intravenous Regular Insulin for the Treatment of Mild and Moderate Diabetic Ketoacidosis in Pediatric Patients. Endocrine, 61, 267-274. https://doi.org/10.1007/s12020-018-1635-Z

[17] American Diabetes Association (2020) 15. Diabetes Care in the Hospital: Standards of Medical Care in Diabetes-2020. Diabetes Care, 43, S193-S202.

https://doi.org/10.2337/dc20-S015

[18] Bellido, V. and Perez, A. (2020) Inpatient Hyperglycemia Management and COVID-19. Diabetes Therapy, 12, 121-132. https://doi.org/10.1007/s13300-020-00966-z

[19] Umpierrez, G., Hellman, R., Korytkowski, M.T., et al. (2012) Management of Hyperglycemia in Hospitalize Patients in Non-Critical Care Setting: An Endocrine Society Clinical Practice Guideline. The Journal of Clinical Endocrinology and Metabolism, 97, 16-38. https://doi.org/10.1210/jc.2011-2098

[20] Ramos, A., Zapata, L., Vera, P., Betbese, A.J. and Perez, A. (2017) Transition from Intravenous Insulin to Subcutaneous Long-Acting Insulin in Critical Care Patients on Enteral or Parenteral Nutrition. Endocrinology, Diabetes and Nutrition, 64, 552-556. https://doi.org/10.1016/j.endinu.2017.08.005

[21] Pasquel, F.J. and Umpierrez, G.E. (2020) Individualizing Inpatient Diabetes Management during the Coronavirus Disease 2019 Pandemic. Journal of Diabetes Science and Technology, 14, 705-707. https://doi.org/10.1177/1932296820923045

[22] Umpierrez, G.E., Cardona, S., Chachkhiani, D., et al. (2018) A Randomized Controlled Study Comparing a DPP4 Inhibitor (Linagliptin) and Basal Insulin (Glargine) in Patients with Type 2 Diabetes in Long-Term Care and Skilled Nursing Facilities: Linagliptin-LTC Trial. Journal of the American Medical Directors Associa- 
tion, 19, 399-404.e3. https://doi.org/10.1016/j.jamda.2017.11.002

[23] Pasquel, F.J., Gianchandani, R., Rubin, D.J., et al. (2017) Efficacy of Sitagliptin for the Hospital Management of General Medicine and Surgery Patients with Type 2 Diabetes (Sita-Hospital): A Multicentre, Prospective, Open-Label, Non-Inferiority Randomised Trial. The Lancet Diabetes \& Endocrinology, 5, 125-133.

https://doi.org/10.1016/S2213-8587(16)30402-8

[24] Cariou, B., Hadjadj, S., Wargny, M., et al. (2020) Phenotypic Characteristics and Prognosis of Inpatients with COVID-19 and Diabetes: The CORONADO Study. Diabetologia, 63, 1500-1515.

[25] Fadini, G.P., Morieri, M.L., Longato, E., et al. (2020) Exposure to Dipeptidyl-peptidase-4 Inhibitors and COVID-19 among People with Type 2 Diabetes: A Case-Control Study. Diabetes, Obesity and Metabolism, 22, 1946-1950.

https://doi.org/10.1111/dom.14097

[26] Bornstein, S.R., Rubino, F., Khunti, K., et al. (2020) Practical Recommendations for the Management of Diabetes in Patients with COVID-19. The Lancet Diabetes \& Endocrinology, 8, 546-550. https://doi.org/10.1016/S2213-8587(20)30152-2 